\title{
Exploring the Challenges of Social-Emotional Learning Integration in Secondary Schools: A Phenomenological Research in Vietnam
}

\author{
Van-Son Huynh' \\ Thien-Vu Giang (D) \\ Thi-Tu Nguyen' \\ Duc-Hoi Dinh ${ }^{2}$ \\ 'Psychology Department, Chi Minh City \\ University of Education, Ho Chi Minh \\ City, Vietnam; ${ }^{2}$ Early Childhood \\ Department, Thai Nguyen University of \\ Education, Thai Nguyen, Vietnam
}

\begin{abstract}
Introduction: With the advantage of the restructured education in Vietnam, the socialemotional learning (SEL) framework has been gradually piloting applied into the educational curriculum. However, the SEL integration is only effective in primary school.

Methods: This study applied qualitative phenomenological research, which used in-depth interviews with students and core teachers who have experienced SEL from previous studies to explore and explain the SEL integration is not successful at the secondary level.

Findings: Four findings showed the current challenges of SEL's integration in Vietnamese educational curriculum: 1) the incompatibility between the current curriculum and the teachers' pedagogical capacity; 2) the perceived difficulties in integrating SEL into educational activities; 3) the limited focus on understanding the students' psychology; and 4) students cannot develop their social-emotional competence.

Discussion: When the challenges can be solved, corresponding to the solutions discussed, can the SEL framework be properly integrated into Vietnamese education, as well as designing an integrated continuous SEL-orientated curriculum across school levels, meeting the requirements of the new educational curriculum.
\end{abstract}

Keywords: social-emotional learning, SEL, social-emotional competence, SEC, secondary school students, phenomenological research, SEL integration

\section{Introduction}

\section{The Current Limitations of SEL Integration in Vietnamese Educational Curriculum}

The national educational curriculum in Vietnam has been successful in restructuring into the new national educational curriculum (or the 2018-general educational curriculum). The country has been piloting to integrate the social-emotional learning (SEL) framework into the educational content. ${ }^{1}$ Kendziora and Yoder argued that the SEL framework is increasingly being adopted by educators as a process of honing life skills that promote personal growth, academic achievement, and a more effective learning environment. ${ }^{2}$ SEL has been integrated into classes and taught in many schools and contributed to many achievements in education. ${ }^{3}$ CASEL has launched the SEL model with implementation guidelines in educational programs. ${ }^{4}$ This model is the foundation for many school-wide programs to elevate socialemotional competence (SEC) for students, parents, and teachers. It advances educational equity and excellence through authentic school-family-community
Correspondence: Thien-Vu Gians Psychology Department, Chi Minh City University of Education, No. 280 an

Duong Vuong St., Ward 4, District 5, Ho Chi Minh City, 700000, Vietnam

Tel +84903056816

Fax +84838398946

Email vugt@phd.hcmue.edu.vn 
partnerships to establish learning environments and experiences that feature trusting and collaborative relationships, rigorous and meaningful curriculum and instruction, and ongoing evaluation. ${ }^{4}$ According to Greenberg et al, the SEL framework can enhance confidence, participation in school activities, improve learning outcomes, and reduce some school mental disorders. ${ }^{3}$ In the long term, students with high SEC are more likely to be willing, confident in college, succeed in their careers, have a positive relationship and better mental health, and become positive citizens in society. SEC is required to be continuously developed from primary school to high school in progress. This has been clarified in a study by Merrell et al. ${ }^{5}$ These researchers applied an SEL framework for continuing education and found that SEL has prevented many mental health issues in school and helped students ac hieve positive learning outcomes. With the impact that SEL brings to students, it is completely in line with the educational orientation to develop the competency and quality of students that Vietnam is implementing in the new national curriculum. ${ }^{6}$ Additionally, the research on integrating SEL into the educational curriculum is an innovative and sustainable development orientation for Vietnam.

From the perspective of developmental psychology, there is a seamlessness in human psychological development. The SEC of secondary school students (SS) will be higher than that of primary school students (PS). ${ }^{7}$ From the educational perspective, the SEC of primary and secondary students is influenced by educational impacts, in particular, the training curriculum and teachers' teaching skills. ${ }^{8}$ In Vietnam, based on the published results about the PS's SEC of Van Huynh, Tran-Chi and Nguyen, and SS's SEC of Van Huynh, Giang, Nguyen and Tran, the SEC of Vietnamese students is unstable and tends to decrease gradually by the educational level. ${ }^{9,10}$ These studies used the Panorama's SEL assessment tool to measure students' mindset, self-efficacy, social awareness, and selfmanagement; one for PS from grade 4 to 5 and one for SS from grade 6 to 9. The PS's SEC self-assessment score is 2.38, while that of the SS is 2.30. This result contradicts all studies of SEL globally.

In Vietnam, studies on SEL frameworks and SELoriented application in schools, especially public schools, are not much and only at the descriptive level. This is the current limit that makes the SEL framework not widely applied and has a strong impact on the development of Vietnamese students. If the SEL's researching trend globally is going from practice to practice, then in Vietnam, it only stops at the level of a theoretical introduction and has not had an impact or adjustment on the educational curriculum. Therefore, this study is designed to explore why the SS's SEC is lower than PS's (2 levels of education have been tested with SEL teaching in government-funded topics), and what the challenges of integrating the SEL framework are in secondary educational level. The findings of the study will be served as evidence for the proposal to effectively and sustainably integrate the SEL framework into the new general educational curriculum, especially for the secondary level, aiming to develop the competencies and qualities of Vietnamese students.

The following section provides a summary of the SEL framework and studies on SEL that have been conducted in Vietnam as a basis for the researchers to select and design appropriate studies.

\section{SEL Framework in Vietnamese Primary and Secondary Education}

SEL is the process through which all young people and adults acquire and apply the knowledge, skills, and attitudes to develop healthy identities, manage emotions and achieve personal and collective goals, feel and show empathy for others, establish and maintain supportive relationships, and make responsible and caring decisions. ${ }^{4}$ In recent years, the SEL framework has been applied in Vietnam, especially at private educational institutions (private schools, and education and training centers). In Vietnam, SEL has not been taught as a single subject. SEL has been integrated into the content of school subjects. ${ }^{10}$ According to Son, since 2017, more than $80 \%$ of private education centers and private schools have focused on SEL in Ho Chi Minh City. ${ }^{11}$ These educational institutions have adopted the SEL framework from other countries such as the Netherlands, the US, Canada, and Switzerland in their institutions, mainly for primary students. This trend has led to a significant increase in the number of students attending these educational institutions over the years. ${ }^{12}$ For public schools, the integration of SEL into educational activities has not been clear. Currently, some public primary schools invited teachers from private life skills training centers to teach life skills for students. ${ }^{13}$ However, SEL has still been considered as an optional subject or extracurricular activity. Formal training of each competence of SEL for students has not been mentioned. It is commonly believed that developing SEC is the 
job of so-called "life skill" teachers, not of teachers of other subjects.

In public secondary schools, SEL has been viewed as extra-curricular activities, flag-yard activities, experiential teaching, and after-school activities. Every year, teachers at all levels are trained on how to integrate SEL into school subjects, but the application is not effective. ${ }^{14}$ Many teachers have not been able to integrate SEL into their subjects and considered it a task of a homeroom teacher/life skills teacher (also as an optional subject). Although the MoET issued the official letter No.463/ BGDDT-GDTX to guide the implementation of life skills education in school, the results were only satisfactory at preschools and primary schools. ${ }^{15}$ Secondary and high schools are still patchy and have not met the requirements of life skills education. ${ }^{14}$

In general, SEL programs in Vietnamese primary and secondary education have not been conducted systematically. This study attempted to explore why the SS's SEC is lower than PS's to find out what the challenges of integrating the SEL framework are in Vietnamese secondary public schools. The study applied an SEL model suggested by Collaborative for Academic, Social, and Emotional Learning with five core competencies: Self-awareness (SeA); Self-management (SM); Social awareness (SoA); Relationship skills (RS); Responsible decision-making (RDM). ${ }^{4}$ The competencies of the SEL model meet the standards of quality (patriotism, compassion, hard-working, honesty, responsibility) and competence (autonomy and self-study, communication and cooperation, problemsolving, and creativity) that Vietnamese students need in the new national education curriculum. ${ }^{6}$ According to the Vietnamese MoET, the educational objectives of primary and secondary education are to equip students with basic knowledge, skills, and attitudes to formulate and develop physical, mental, and social competence for them, to prepare them to be able to adapt and develop healthily to the new social requirements. ${ }^{6}$ This educational orientation is perfectly aligned with the destination of the SEL. Therefore, the research on the application of the SEL model in educational activities in Vietnam guaranteed the requirements for restructuring the new curriculum.

\section{Methods}

\section{Study Design}

With the synthesis and lessons learned from SEL's previous studies as well as the studies on the content of the new Vietnamese national educational curriculum, this study was conducted to explore why the SS's SEC is lower than PS's, and why the SEL framework is not possible to mass deploy in secondary public schools. The expected findings would propose the SEL educational orientations for restructuring the educational activities in schools as well as the new national educational curriculum. For this mission, the study has been done by Ho Chi Minh City University of Education's Psychology and Education Potential Research Team from 2018 to 2020. This research team is licensed by the Vietnamese MoET in the implementation of research projects on national educational innovation. Also, previous SEL studies in Vietnam were conducted by this research team. ${ }^{9,10}$ Therefore, inheriting and continuing to study the limitations that the previous topics have not yet implemented is feasible and necessary.

With this research question, this study applied a qualitative approach aiming to find answers to how the development of SEC changes between the two levels of education and what the challenges of integrating SEL in secondary schools are. According to Creswell and Poth to understand deeply a phenomenon from the experience of the participants and to find the essence of it, phenomenological research is appreciated. ${ }^{16}$ In this study, the researchers want to find out the essence of the SEC development between primary and secondary school students which helps the researchers propose the application solutions for the continuous SEL education from primary to secondary education in Vietnam. Therefore, applying phenomenological research is the best suitable approach for answering this research question.

\section{Procedure}

Based on the theory and empirical results of the application of SEL in education by Merrell et al, and Beamish and Bryer, the student's SEC will steadily increase across different educational levels, as evidenced by significant improvements in academic achievement, learning outcome, mental health, relationships, and social adaptation. ${ }^{5,7}$ However, this result is not rational when applied in Vietnam. Therefore, the in-depth inquiry was made through interviews with people who have experienced SEL (students, teachers, school administrators) on the impact of SEL, and the application of SEL in Vietnamese primary and secondary schools are essential. ${ }^{9,10} 1004$ PS, 509 SS, 250 primary teachers and primary school administrators, 140 secondary teachers 
and secondary school administrators from 8 primary schools and 8 secondary schools in 3 major cities directly under the Vietnamese central government participated in previous studies were contacted to take part in this study. ${ }^{9,10}$ Table 1 shows basic information on the 14-participating PS and SS in this study based on their willingness and their school administrators, teachers, and parents' permission (See Table 1). For teachers and administrators, 10 primary school and secondary school teachers and administrators participated in this study based on their willingness. Table 2 provides basic information on participating teachers and administrators (see Table 2).

Based on the analysis of the application of SEL in Vietnamese schools, it can be seen that SEL has been integrated as content in different subjects such as Mathematics, Literature, History, Geography, Civic education, especially Life-skills education. ${ }^{10,13,14}$ As a result, students will not be fully aware of SEL, or even know what it is. Therefore, to find out students' understanding of SEL, in-depth interviews combined with behavioral observations are required based on the criteria of the 5 core competencies of the SEL model. Because previous studies focused on raising students' perception of SEL, and training students' social-emotional skills, the interview questions were centered around their understanding and experiences with SEL and social-emotional skills. Openended questions about SeA, SM, SoA, RS, and RDM, are needed to unravel the SEC of Vietnamese students (interviewed in person):

Table I The Interview Students' Description

\begin{tabular}{|c|c|c|c|c|c|c|}
\hline Educational Level & Code & Grade & Age & School & Academic Achievement & Gender \\
\hline \multirow[t]{7}{*}{ Primary school students } & PSI & 4 & 10 & HVC, HCMC & Good & Male \\
\hline & PS2 & 4 & 10 & LL, DNC & Good & Male \\
\hline & PS3 & 4 & 10 & TSN, CTC & Good & Female \\
\hline & PS3 & 5 & 11 & LL, DNC & Good & Female \\
\hline & PS4 & 5 & 11 & PCT, HCMC & Good & Female \\
\hline & PS5 & 5 & 11 & LTT, HCMC & Good & Female \\
\hline & PS6 & 5 & 11 & TSN, CTC & Good & Male \\
\hline \multirow[t]{8}{*}{ Secondary school students } & SSI & 6 & 12 & ND, HCMC & Good & Male \\
\hline & SS2 & 6 & 12 & ND, HCMC & Fair & Female \\
\hline & SS3 & 7 & 13 & $\mathrm{NH}, \mathrm{DNC}$ & Average & Male \\
\hline & SS4 & 8 & 14 & НВТ, СТС & Good & Male \\
\hline & SS5 & 8 & 14 & VTT, HCMC & Average & Male \\
\hline & SS6 & 9 & 15 & VTT, HCMC & Average & Female \\
\hline & SS7 & 9 & 15 & НВТ, СТС & Good & Female \\
\hline & SS8 & 9 & 15 & ND, HCMC & Fair & Male \\
\hline
\end{tabular}

Abbreviations: HCMC, Ho Chi Minh City, Vietnam; CTC, Can Tho City, Vietnam; DNC, Da Nang City, Vietnam.

Table 2 The Interview Core Teachers' Description

\begin{tabular}{|l|c|c|c|c|c|c|c|}
\hline School & Code & Age & Year of Teaching & Academic Background & Position & Gender & School \\
\hline Primary school & PTI & 30 & 7 & Bachelor & Senior teacher & Female & LTT, HCMC \\
& PT2 & 32 & 10 & Bachelor & Professional leader & $\begin{array}{c}\text { Female } \\
\text { LL, DC }\end{array}$ \\
\hline \multirow{3}{*}{ Secondary school } & STI & 40 & 16 & Bachelor & Professional leader & Female & ND, HCMC \\
& ST2 & 40 & 18 & Bachelor & Professional leader & Female & HBT, CTC \\
& ST3 & 36 & 12 & Master & School administrator & Male & ND, HCMC \\
& ST4 & 38 & 16 & Bachelor & Professional leader & Female & ND, HCMC \\
& ST5 & 45 & 23 & Master & School administrator & Female & HBT, CTC \\
& ST6 & 48 & 26 & Master & School administrator & Female & VTT, HCMC \\
& ST7 & 32 & 10 & Bachelor & Professional leader & Male & ND, HCMC \\
& ST8 & 29 & 6 & Bachelor & Senior teacher & Male & VTT, HCMC \\
\hline
\end{tabular}

Abbreviations: HCMC, Ho Chi Minh City, Vietnam; CTC, Can Tho City, Vietnam; DNC, Da Nang City, Vietnam. 
(1) How do you understand SEL?

(2) Please share your knowledge and experiences with SEL or the social-emotional skills.

With the inadequacy in SEL of students, the main participants of this study are teachers and school administrators, who directly apply SEL in schools.

This study was approved by the Department of Science and Technology - Ethics committee of Ho Chi Minh City University of Education (under the Vietnamese MoET) and in accordance with the Declaration of Helsinki. Participants were fully informed regarding the interview prior. Participation in interviewing was considered a proxy consent to participate. For students, the parental or legal guardian informed consents were obtained before participating. All participants were optional, we also used nonidentifying codes, ensuring the confidentiality of the information.

To explore which challenges made the teachers and school administrators fail to integrate the SEL framework in schools, in-depth interviews were conducted with 4 questions (interviewed in person). The 4-questions were developed based on teachers' understanding of SEL trained, their praticed experience, and their evaluation after participating in previous studies:

1. How do you understand of SEL?

2. How have you integrated SEL in your educational activities?

3. What are your experiences with integrating SEL in the current educational curriculum?

4. How would you evaluate the impact of SEL on students?

Ten teachers and administrators who participated in the interview were the core teachers participating in the national training course on restructuring the new national educational curriculum, including the application of SEL in educational activities. Core teachers are those with at least 5-years of teaching experience, professional qualifications, and academic qualifications that meet the new requirements of the Vietnamese education system; also, they are professional leaders, school administrators, senior teachers in schools. ${ }^{17}$ From here, we will code the term "teachers" and "school administrators" as core teachers.

\section{Data Analysis}

The phenomenological method was used in analyzing the participants' transcripts. In this method, all written transcripts are read several times to get an overall feeling for them. Two authors independently were responsible for the interpretation of transcript by PS - primary core teachers and SS - secondary core teachers. Then, pass to the other two authors for cross-review. In the end, all four authors met to agree on the themes of analysis. From each transcript, key phrases or sentences directly related to the experience of SEL (through the behavior and perception of the five core competencies of SEL) are identified. The meaning is then made up of essential sentences and phrases. Formula meanings are grouped into themes that allow for popular themes to appear on all participant transcripts. The results are then integrated into a complete, insightful description of this phenomenon. After the description and topic have been obtained, the researchers at the final step can approach several participants a second time to confirm the results. If new relevant data appears, they are included in the final description.

This study employed a thematic approach in the analysis of interview data. ${ }^{18}$ Key themes emerged from the analysis. All quotations cited in this paper have been supported and analysed by ATLAS.ti software, then translated from Vietnamese to English from interview transcripts. The findings are presented as a theme that represents the overall result of how Vietnamese PS and SS understanding SEL, and how Vietnamese core teachers facing challenges when integrating SEL in educational activities. Based on the findings, the researchers discovered how the change or the development in SEC between PS and SS, to propose the continuous application solutions in the curriculum (eg, educational activities) from primary to secondary education level which can overcome the current limitations.

Table 3 describes how the researchers divided the themes and sub-themes based on the interview quotes. These themes and sub-themes have been agreed upon through the discussion and handling between the three members working independently in the research team (See Table 3).

\section{Findings}

\section{Students: Confusion Between SEL and Life Skills}

Interviews with PS and SS participated in the study reflected several confused perceptions between SEL and life skills. According to WHO, life skills include 6 areas: Communication and interpersonal skills; Decision-making 
Table 3 Coding Interview Quotes into Themes and Sub-Themes Description

\begin{tabular}{|c|c|c|c|}
\hline Participants & Themes & Sub-Themes & Interview Quotes \\
\hline Students & $\begin{array}{l}\text { Confusion between SEL } \\
\text { and life skills }\end{array}$ & & $\begin{array}{l}\text { - I do not understand what social-emotional competencies } \\
\text { are, but I do know that life skills teach me emotional } \\
\text { management as well as social interaction skills. } \\
\text { - I do not know if there is any difference between life skills } \\
\text { and social-emotional skills. I asked my teacher, however, their } \\
\text { answers were the same, so I could not tell. }\end{array}$ \\
\hline \multirow[t]{3}{*}{$\begin{array}{l}\text { Core } \\
\text { teachers }\end{array}$} & \multirow[t]{3}{*}{$\begin{array}{l}\text { Not fully understand and } \\
\text { not successfully implement } \\
\text { SEL in schools }\end{array}$} & $\begin{array}{l}\text { Limited time for SEL program in } \\
\text { the current secondary education } \\
\text { curriculum }\end{array}$ & $\begin{array}{l}\text { - The students were in the class too much and hardly had time } \\
\text { for personal activities, entertainment, and life skill training. } \\
\text { - The secondary subjects are too academic and do not combine } \\
\text { with training life skills. This has been leading to a situation that } \\
\text { many students are now facing difficulties and pressure to study. }\end{array}$ \\
\hline & & $\begin{array}{l}\text { Perceived difficulties to integrate } \\
\text { SEL into educational activities in } \\
\text { secondary school }\end{array}$ & $\begin{array}{l}\text { - The classroom will become disorganized when you put } \\
\text { students in too much activity without taking measures to } \\
\text { keep them organized. } \\
\text { - I have been trained on how to apply SEL in teaching. However, I } \\
\text { cannot organize SEL activities in my Geography lessons. }\end{array}$ \\
\hline & & $\begin{array}{l}\text { Limited focus on understanding the } \\
\text { psychological development of SS }\end{array}$ & $\begin{array}{l}\text { - They need care and understanding from friends, family, and } \\
\text { teachers. But in reality, there is a gap between Vietnamese } \\
\text { teachers and students. } \\
\text { - I do not understand deeply about the psychological change } \\
\text { in puberty age. My students said that I often impose these } \\
\text { contents and they sometimes oppose me. }\end{array}$ \\
\hline
\end{tabular}

and problem-solving; Creative thinking and critical thinking; Self-awareness and empathy; Assertiveness and equanimity, or self-control; Resilience and ability to cope with problems. ${ }^{19}$ Any skill that is useful in your life can be considered a life skill. Meanwhile, SEL encompasses human knowledge, skills, and attitudes in self-awareness, social awareness, self-management, relationship building, and responsible decision-making. Therefore, SEL is a part of life skills and does not have the same coverage as life skills. Many students believe that SEL is a life-skill and using SEL is practicing the skills they have learned.

'I have learned about self-awareness [SeA], emotional management [SM], establishing relationships [RS], and making problem-solving decisions $[\mathrm{RDM}]$ in life skills class. I enjoy learning life skills because it is a subject with many practical applications.' (PS1)

'My life skills teacher taught me many ways of managing emotions [SM], and also ways to communicate and get to know others [SoA, RS]. This is a very useful subject.' (PS2)

'I do not understand what social-emotional competencies are, but I do know that life skills teach me emotional management [SM] as well as social interaction skills [RS, SoA].' (SS1)

'Social-emotional competence is a life skill. Learning good life skills will have good social-emotional competence and vice versa. My teacher taught me like that.' (PS3)

This viewpoint is not wrong, but confusing. It will be a huge barrier for educators and researchers when the perception of SEL is identified with life skills. This will make it difficult to implement SEL programs in Vietnamese education because the life skills education program has been implemented effectively for more than 10 years. ${ }^{12}$ No one will want to change an effective and diversified lifeskills education program with an SEL program limited to the socio-emotional aspect. Because in essence, Vietnamese education aims to develop the comprehensive human personality, not only in socio-emotional aspects.

Many students feel confused when they have to learn many skill periods in a week. This leads to the students not clearly understand what they are learning and what to learn.

'In my class, I have to learn three skill periods in one week, one on social skills, one on life skills, and one on 
life values. Studying so many skill periods with different names makes me unable to distinguish, and even the content itself is very similar.' (SS2)

'My school often organizes life skills competitions, while practical lessons are about social-emotional skills. I do not know if there is any difference between life skills and social-emotional skills. I asked my teacher, however, their answers were the same, so I could not tell.' (SS3)

PS and SS's interview data shows that they are equipped with SEL knowledge and skills. However, they do not know that it is SEL and identify that knowledge and skills as an application orientation in the subjects that teachers instruct them to implement.

For PS, they listen to what their teachers teach and believe that practicing the life skills they learn is a way of demonstrating that they have SEC. Three students shared that:

'In Nature and Society subject, my teacher teaches me how to deal with strangers [SoA, RS, RDM] and express my feelings for others [SM, RS]. The Physical Education teacher teaches me how to protect myself [RDM, SeA, $\mathrm{SM}$ ] and release my emotions with appropriate exercise [SeA, SM].' (PS4)

'In Civics Education, the teacher teaches me how to be responsible for my words and actions [SeA, RDM].' (PS5)

'I learn how to understand and express my feelings, establish relationships with others and make responsible decisions [RDM] in most subjects: Math, Vietnamese, English, Arts, Music, History, Geography, Science ... Any subject helps me improve my ability to understand myself [SeA, SM] and adapt to life [SoA, RS].' (PS6)

In addition to being integrated into the content of the subjects, in primary schools, students also experience various types of SEL education through extracurricular activities. One student reported:

'My school regularly organizes life-skill playgrounds outside of school hours. At these playgrounds, I and my friends experience a lot of different skills, including emotional management [SeA, SM], self-awareness [SeA], safe behavior [SoA, RS], self-protection [SM], friend connection $[\mathrm{SoA}, \mathrm{RS}]$, creative thinking $[\mathrm{SeA}] \ldots \mathrm{I}$ am very interested in participating in these playgrounds because in addition to learning and playing, I also make new friends [RS].' (PS5)

For SS, there is almost no formal learning period for SEL during school hours in public schools. Therefore, the SEL framework is integrated into all subjects, especially in Life Skills Education. Moreover, the cognitive development by age also helps SS to better understand the SEC, but only in terms of the applied orientation of the subject. Some SSs shared that:

'The ability to recognize others' emotions [SoA], as well as express appropriate emotions in relationships [SoA, RS] that I currently have, is thanks to my Literature teacher. Without Literature, I would not be able to become a sympathetic person [SeA].' (SS4)

'Life Skills Education is a subject with many applications. I have the opportunity to learn about myself [SeA], recognize my strengths and limitations [SeA], and then make appropriate learning decisions [RDM]. Not only that, but I am also equipped with social communication skills to effectively interact when participating in other social activities [SoA, RS].' (SS5)

Other SSs held quite negative views on the training of social and emotional skills at school. One student commented:

'My life-skill teacher is not good at teaching. She only teaches theory, I hardly practice. She always talks about her feelings, never cares about mine [SM, SoA]. Just because am I an average student?' (SS6)

Another highly performing SS shared her opinion about learning social and emotional skills at school with SS6. She reported that:

'My life-skill teacher teaches skills without skills at all. He taught me how to communicate, speak loudly, and clearly [RS, SoA]; while he spoke very softly, stumbled, and was not confident. Also, many questions about my feelings that he could not answer [SoA].' (SS7)

Another SS showed more interest in social skills training extracurricular activities than the formal lessons in class. He said:

'I prefer to participate in outdoor skills training activities. Especially the workshop in mental health, emotion, selfawareness, career orientation, and life goals [SeA, SM, SoA, RS, RDM]. The class hours did not appeal to me because most of the skills learned in the Life Skill Education subject were guided by teachers in other subjects.' (SS8)

Thus, PS or SS have been experienced SEL in terms of integrating content into different subjects. Some schools integrated the SEL framework into their part-time 
educational activities. However, it is ineffective for students to experience but not determine what they are experiencing. Additionally, it was found that the limited problem of teachers' pedagogical capacities was discovered in the student's responses. Especially, teachers do not understand of SEL but have integrated SEL. To better understand this issue, the next section will present findings from core teachers in applying SEL in educational activities at schools.

\section{Core Teachers: Not Fully Understand and Not Successfully Implement SEL in Schools}

SEL framework in Vietnam is implemented into the public educational curriculum in the form of life skills training and extracurricular educational activities. Therefore, the results of interviews with core teachers reflected their perceptions of SEL as a form of implementation of life skills education. We will not separate SEL and life skills in the findings' analysis.

\section{Limited Time for SEL Program in the Current Secondary Education Curriculum}

Interviews with core teachers show the reasons for the reported lower SEC of Vietnamese SS found in previous studies. Many core teachers believed that the changes in the current curriculum of the two educational levels are one of the factors contributing to the students' SEC.

The interview with secondary teachers confirmed the information. One of them stated:

\footnotetext{
'The current secondary education curriculum is too academic, and students have to study 8-9 periods a day to meet the program's requirements. There is no time set for teachers to organize life skills activities and SEL enhancement activities for students ... A lot of our teachers are trying to integrate SEL into the school subject, but I feel ineffective. Students tend to be overwhelmed and under great pressure ...' (ST1)
}

Primary teachers reported that they received information from parents of their ex-students who complained that their children had limited time for developing SEC at secondary school. Two of them said:

'Currently, my school organized life skills activities in the form of games for students to be relaxed, learning, and experiencing. I always stress the great importance of emotional education for students, helping them to identify and manage their emotions well. But when my students went to secondary school, many parents called me to share the status of their children. The students were in the class too much and hardly had time for personal activities, entertainment, and life skill training. Therefore, many students fall into anxiety and stress.' (PT1)

'... when my students transfer to secondary school (grade 6), many of them were surprised when the curriculum changes a lot, and they had limited time for life skills activities. Also, the secondary subjects are too academic and do not combine with training life skills. This has been leading to a situation that many students are now facing difficulties and pressure to study ... '. (PT2)

The interview data shows that the current secondary education curriculum seems to be too academic and has limited time for SEL programs. This was perceived as one of the reasons why the SEC of SS was lower than that of PS. When students are in the secondary school environment, they are under pressure of grades, tests, and examinations. Besides, the average number of subjects a secondary school student must learn is 14 subjects, while the average number of subjects a PS in 10 subjects. The increase in the number of subjects, as well as the deep specialization in secondary subjects (Natural - Social Science is divided into 5 different subjects: Physics, Chemistry, Biology, History, Geography), make SS have to focus a lot on learning and reduce their participation in other skills training and extra-curricular activities. Therefore, it could be perceived that SS had limited space for the SEL program in their schools and it could be the reason for the decrease in SEC of SS.

\section{Perceived Difficulties to Integrate SEL into Educational Activities in Secondary School}

Teachers during the interviews believed that they faced many difficulties in integrating SEL into educational activities, mainly the integrated methods and SEL teaching methodology.

First of all, teachers reported that they were not successful in integrating SEL into their subjects. Many teachers said they had been trained on SEL as well as on how to integrate SEL into teaching activities. However, they believed that integration was possible "in theory" only. Teachers reported that they faced many difficulties integrating SEL into educational activities in practice. This was believed to inadvertently create pressure for students (especially SS).

Even one secondary teacher claimed that SEL should not be integrated into educational activities, especially life skill education. She said: 
'If teachers try to integrate SEL in the teaching hours, some students reflect that they do not like the teaching method of teachers. Students seem not to be able to learn the subject nor SEL ... My students refer to study life skills in a separate lesson.' (ST2)

Another secondary teacher shared his experience as follows:

'Life skills and SEC have the same contents when composing a lesson plan ... for years my school has tried to integrate life skills content into educational activities in the school, but still theoretical and stereotyped. Many teachers are mistaken for the role of life skills and the methods to teach a life skill. They just give lectures and exercises like many other subject, their life skills lessons are very theoretical. Students are not interested in the lessons. This is a problem that needs to be considered and appropriate solutions are to be found because if teachers do not know how to teach a life skill lesson, you can not apply the SEL model into any educational activities.' (ST3)

A secondary teacher felt confused about how to apply SEL into activities in class because it easily made the class chaotic and messy. Moreover, she perceived that teaching SEL was the life-skill teacher's job, not the responsibility of a subject teacher.

'... I want to use games to integrate SEL content into my math lessons, but I could not. The classroom will become disorganized when you put students in too much activity without taking measures to keep them organized ... My school has invited life-skill teachers in the past 2 years, I find the way they implement SEL in educational activities very effectively. My homeroom class is very interested when learning life-skill. I left the SEL teaching to the life-skills teacher. I cannot apply SEL. They teach it good than me.' (ST4)

A secondary school teacher stated that integrating SEL into a specific subject did not bring positive results. She said:

'I have been trained on how to apply SEL in teaching. However, I cannot organize SEL activities in my Geography lessons. When I integrated the SoA content into the lesson - The characteristics of the people in the Mekong Delta, I almost taught about SoA. I was completely unable to mention the knowledge of the lesson ... I have tried many times but failed. I had to skip SEL and teach the lesson to ensure the teaching progress.' (ST5)
Due to the identification of SEL as a life skill, core teachers do not fully understand of SEL, and as a result, the way they integrate SEL into educational activities is no different from a passive teaching activity. Not only that, core teachers' pedagogical skills, especially SEL teaching methods, are an issue that needs to be addressed because of the fact that teachers do not integrate SEL successfully.

\section{Limited Focus on Understanding the Psychological Development of SS}

The data from interviews show that the psychological development of SS has not been paid sufficient attention. Some issue of gender education, school counseling, or enhancing the understanding - the communication between teachers and students at present in secondary schools is still quite limited, thus affecting the SEC of SS. At this age of puberty, what SS needs most is care, sharing, and understanding.

One secondary school teacher shared her experience in teaching SS for many years.

'At secondary school age, students have many psychological changes, especially in the 7 th and 8 th grades. At this age, their emotion changes very intensely, sometimes selfproclaimed, overdoing it directly. Many students gradually lose their orientation, they do not know what they want and should do. They are vulnerable to the influence of others and are easily dragged into unsafe relationships. They need care and understanding from friends, family, and teachers. But in reality, there is a gap between Vietnamese teachers and students. The school counseling work has not been paid attention to my school. My students almost solve the problems by themselves.' (ST6)

Another secondary school teacher said.

'The current secondary education program is too knowledgeable, lack of practice, and lessons on life skills, psychophysiological issues, gender education. Most of my students who have psychological problems have learned by themselves. They are afraid to share that with their teachers and parents. The counseling office at my school is also operated by a Literature teacher so not many students come. If they do not receive the sharing, sympathy, guidance on gender issues, will greatly affect their academic performance and mental health ...' (ST7)

A secondary school teacher also agreed that the SEC of SS will be greatly reduced due to the psychological changes along with the non-response in the content of life skills education and gender education in schools: 
'... Even if I mention the SEL content during my lesson, it did not work. I found that I mentioned too much about my life experiences, I do not understand deeply about the psychological change in puberty age. My students said that I often impose these contents and they sometimes oppose me ...' (ST8)

Core teachers do not fully understand the psychological characteristics of SS, which lead to them having difficulty and uncomfortable in handling their students' problems. This leads to an extrusion of responsibility for the school counselor.

Obviously, based on the views of the current participants, the beliefs, values and expectations of core teachers in integrating SEL into educational activities are the challenges and this is a major barrier to overcome if Vietnam want to integrate SEL into secondary education. If teachers do not change their perception of SEL that it is an interdisciplinary education, not just a certain department's responsibility; will not be able to integrate SEL successfully into educational curriculum.

\section{Discussion}

This study was designed to answer what the challenges of integrating SEL in secondary schools are in the Vietnamese context, by using interviews in a phenomenological study with Vietnamese core teachers and students. Based on the views of the current participants, the challenges in core teachers' perception and pedagogical capacities that made the failure of integration SEL in secondary schools. This would propose orientations for renovating the national secondary educational curriculum, especially the continuous SEL educational program from primary to secondary school. Data from interviews with 10 primary and secondary school core teachers to some extent showed the four reasons why the SEC of SS was lower than PS: (1) the incompatibility between the current Vietnamese curriculum and the pedagogical capacity of the teachers; (2) the perceived difficulties in integrating SEL into educational activities; (3) the limited focus on understanding the psychological development of SS in the curriculum and educational programs/activities; and (4) students themselves cannot develop their SEC. Thus, there were both objectives (the current secondary educational program did not meet the contents of the SEL framework) and subjective factors (the capacity to apply the SEL model to educational activities of teachers) affected the SEC impairment of SS. With the findings from the thematic analysis, the researchers make the following discussions.

\section{Strengthen Teacher Training and Retraining Programs on SEL and School Mental Health Issues for Core Teachers to Improve Their Adoption and Practice Capacity}

With findings of limited core teacher's understanding of SEL and application capacity of SEL, SEL application training for core teachers on SEL's definition, SEL's essence, how to teach, as well as designing SEL-oriented educational activities, is necessary. In other words, the essence of core teachers' lack of understanding of SEL and inability to apply SEL is misperception of coordination and interdisciplinary education on SEL. Therefore, they do not have the suitable SEL-oriented teaching methods. Particularly, the content that needed clarifying for core teachers about SEL should ensure: The framework can be integrated into specific subjects or designed into an educational activity. It is not feasible to teach SEL as a separate subject and the coordination of teachers, schools, parents and community is required in the SEL education for students. Therefore, it is highly feasible and practical to guide core teachers to incorporate the contents of SEL into their subjects and other educational activities. Firstly, using active teaching methods (project-based learning, problem-solving based learning, discovery-based learning, experimental-based learning, responsive-based learning), promoting students' group activities, encouraging debate, and share ideas with friends and teachers, especially improve the positive interaction between teachers and students (reinforce the SoA, RS, and RDM). After each lesson, the teachers apply the meta-reflection technique, which helps students re-reflect on the knowledge learned in the lesson, as well as share their views, opinions, and feelings about the lesson that day (reinforce the SeA and SM). Secondly, increasing the students learn in advance the lesson content at home (the basic content), when going to class, students will present what they have researched and understood for the whole class to discuss. The teacher will be the one to summarize the lesson message. With this learning method, it helps students practice SeA and SM competencies at home, but also encourages them to practice SoA, RS, and RDM competencies during class time, towards comprehensive SEL training. With this changing orientation of teaching methods, it is possible to overcome 
the problem of time constraints in applying SEL in schools, especially in secondary schools. The application of these two measures is easier to implement for secondary school students - the age of high self-awareness in learning. This will be a prerequisite for Vietnamese students' SEC to develop in an upward trend from primary to secondary school.

With findings of limited teachers' understanding of psychological development of students from PS to SS, training for teachers on the relationship between SEC and human psychological development (students) must be focused in the early stages before specialized training the SEL framework. SEL's five core competencies have theoretical foundations from psychology. Golinkoff and Hirsh-Pasek affirmed that the basic characteristics and development of human cognition, emotion, and personality function will profoundly affect their social behavior and SEC. ${ }^{20}$ Yang et al also showed that students' SEC development is strongly correlated with human age-related psychological development. ${ }^{21}$ Therefore, the development of SEC cannot be separated from the development of human psychology in teaching. To overcome this limitation, in the teacher training program, it is necessary to repeat the content of the psychological characteristics of the students by age, then the characteristics of the SEC, and finally linking these two groups of knowledge are together so that teachers can understand this interaction. Besides, additional training is also needed about the impact of the SEC on the mental health of students of different ages, especially SS. For example, if SeA and SM competencies are limited, it will be difficult for SS to overcome the psychological crisis of puberty, targeting sex determination, career orientation, friendship relationships, and family, or other mental problems (depression, suicidal thoughts, PTSD, etc). Also, training teachers how to increase empathy, compassion, and well-being in the classroom to create a positive, healthy learning environment for students is also an interesting orientation to develop the students' SEC. To do so, first of all, the teacher must feel happy at work, have to have sympathy for himself to be able to show sympathy, and helping students develop happiness. $^{22-24}$ This finding shows the need and role of school psychologists to accompany and support teachers in developing SEC for students. However, core teachers need to be aware of mental care and creating a safe, healthy school climate is a common responsibility of all educational forces, requires interdisciplinary coordination, not just is the duty of the school psychologist.
In summary, Vietnamese teachers should be trained not only on the content of the SEL framework but also on how to implement SEL-oriented educational activities and understand the psychological characteristics of students.

\section{Promote Communication and Education to Improve the Students' and Core Teachers' Perception About SEL}

From the findings, it can be seen that not only core teachers but also students need to improve their understanding of SEL. Currently, there are two problems about SEL among students, one is the confusion between the content of SEL and life skills, the other is only learning and not caring what they learn. The problem of students not being able to develop their own SEC is because they do not understand what the SEC is, and why it is necessary to receive SEL. With this problem, not only teachers - the practitioners, applying SEL in schools, but also school administrators, school staff also need to distinguish the term SEL and life skills, as this is forced directly teaching, as well as supporting communication, counseling, and knowledge for students to understand correctly about SEL. Having a correct understanding can apply correctly and know what we learn, what to do, and what to develop. According to UNESCO's life skills classification, there are 3 main skill groups: (1) basic skills, (2) general skills, and (3) situation, context, and problem-based skills. According to WHO, life skills are classified into 3 groups: (1) group of cognitive skills, (2) group of social skills, (3) group of emotional skills. According to UNICEF, life skills are classified into three groups: (1) social skills, (2) cognitive development skills, and (3) skills to deal with emotions and self-control. ${ }^{19}$ With the SEL framework, five specific skills are focused on self-awareness skills, social awareness skills, self-management skills, relationship skills, and responsible decision-making skills. ${ }^{4}$ According to these theoretical frameworks, it can be affirmed that the contents of SEL are narrower than life skills. The skills in SEL do not cover all life skills and cannot help students adapt, develop, and cope with different life challenges (such as career choices, survival, hard skills are required to meet specific careers). The skills in the SEL framework, or SEC, only help develop a focus on emotional and social aspects. A deeper explanation shows, SEL can help students practice skills to develop and cope with life challenges, but it cannot be said that SEL can fully shape or develop students' life skills, especially in context of each 
student and the constant change in social life. SEL is an important contributor to relationship and career outcomes, but in fact shows that life skills vary, as well as cover many different contexts. In some specific careers, for example, people do not often interact with colleagues, the work does not have many challenges related to communication or interaction, life skills and soft skills will contribute more to success and happiness. SEL is very important, but in fact SEL adoption differs from country to country, especially in that the deployment of SEL depends heavily on adoption, which is influenced by the implementer's SEC and background experiences. Therefore, it is important to look multidimensional, to avoid assuming that the SEL is original in each country. Only when it helps teachers, school staff (through the training content), and students understand correctly about SEL, then can they properly and effectively apply in life.

From here, the researchers suggest ways to improve students' understanding by enhancing SEL awarenessenhancing communication activities (class message boards, social media articles, leaflets, school radio, schoolyard seminars), at the same time, in the teaching activity in all subjects, there is a need to add an Application Orientation activity - to guide students in combination lesson content with SEC to self-develop and apply lessons in real life. Also, the differences in perceptions of PS and SS should be considered when implementing communication measures. The role of a school psychologist is essential in providing advice, assisting teachers in using words by student's psychology, as well as appropriate SEL education and communication.

\section{Apply SEL Framework Gradually Due to the Characteristic of the Vietnamese Educational Curriculum}

The Vietnamese educational curriculum has the characteristics that are both advantages and challenges when applying the SEL framework to (1) the program emphasizes the development of students' competencies and qualities through knowledge and practice; (2) the program ensures connectivity between grades, classes, and cross-learning; (3) the curriculum is designed in an open direction. ${ }^{6}$ SEL framework can help develop competencies and qualities by training students' socio-emotional skills not only within one grade level but also throughout the development and learning process. Besides, with the essence of skills and living values training, the SEL framework must be applied sincerely, in line with the Vietnamese educational program.

Therefore, it is possible and necessary to refer to lessons learned from countries where SEL has been successfully applied. International previous studies showed that there were currently three main measures to apply SEL to schools: (1) Integrating SEL in school subjects: In 2009, the Philippine Ministry of Education and Training planned to include the SEL education model into the curriculum of public schools to develop students' emotional quotient (EQ) in addition to the previous IQ. SEL had been integrated into Personality Education to develop self-awareness, self-management, social awareness, social skills, and responsible decision-making; (2) Selecting SEL program appropriate to the conditions of the school and teach as a separate subject: Currently in the UK, with an effort to unify and provide clear benefits to all students, over the past 5 years the MoET had developed programs for the UK, covering all ages. ${ }^{25,26}$ These programs were collectively known as "Social and Emotional Aspects of Learning" (SEAL). Currently, SEAL has been being implemented in about $90 \%$ of primary schools and $70 \%$ of secondary schools in the UK as a separated content (Humphrey et al, 2010); (3) Applying SEL as a guideline operating in all areas of school activities: national CASEL program in Singapore. ${ }^{27}$ These measures met the student competence development orientation that Vietnam has been implementing. In particular, with the approach of integrating SEL into the curriculum, Vietnam is testing this approach. ${ }^{9,10,14}$ However, the feedback results show that it is not effective and feasible. Vietnamese curriculum is quite knowledge-intensive, while the SEL framework is more inclined to practice skills. If this gap can be bridged, the integration of SEL in the curriculum will see a new step. We suggest that, in the newly deployed national educational program, all subjects have about $20-30 \%$ of the program for students to experience and practice the subject. This capacity is suitable for importing SEL content. The integration of SEL in the experiential lessons will be implemented in the form of career experiences, skills practice related to that subject in the form of business experience (Mathematics, Physic, Chemistry, Technology), scientific discovery (Biology, Geography, Physic, Chemistry), learning historical-cultural relics (History, Civic Education, Geography, Literature), social work (Literature, Civic Education, Extracurricular activities, Club activities), etc. In terms of implementation, the content of SEL should be included in grade 1, gradually 
progressing through the academic years, continuing to grade 1,2, and 6 after that, the next academic year will continue to be $1,2,3,6,7$ and 10 . The gradual in applying SEL into the curriculum will enable teachers to learn from the previous academic year and to prepare in time to implement and integrate SEL in any subjects.

In general, through the findings from interview data, it could be possible to build an SEL-continuing educational program that is oriented towards student competence development through the education level. As long as the staff implementing this educational program understands the essence of SEL, as well as has SEL-teaching methods appropriate to the psychological characteristics of Vietnamese students.

\section{Conclusion}

Although the SEL framework has been applied in Vietnam for many years, and initially achieved certain achievements in education, there are still many shortcomings. First, the application of SEL in schools and educational institutions is heterogeneous, leading to difficulties in understanding and manipulating SEL, especially when students change from primary to secondary schools. Second, SEL teachers do not have a clear understanding of the essence of SEL, leading to ineffective teaching and misunderstandings about SEL. Third, there is too much confusion between SEL and life skills education in legal documents on the development of students' competencies and qualities. By using the in-depth interview in the phenomenological research of qualitative approach, the researchers have discovered four main reasons for the inadequacies of SEL when applied in Vietnamese schools, especially to answer the question of why there is a backward difference in the SEC between PS and SS. This is also the challenges that SEL is facing when implementing in the Vietnamese educational curriculum, especially the secondary level: (1) the incompatibility between the current Vietnamese curriculum and the pedagogical capacity of the teachers; (2) the perceived difficulties in integrating SEL into educational activities; (3) the limited focus on understanding the psychological development of SS; and (4) students themselves cannot develop their socio-emotional competencies.

Based on these findings, the researchers recommend remedies, with a focus on designing topics to train teachers in understanding the essence of SEL, on SEL-oriented teaching methods, and the relationship between SEC and student age psychology. By discovering why teachers did not integrate SEL successfully, leading to a lower SS's SEC than PS's.
The researchers found that, if teachers were unable to differentiate SEL and life skills education, without understanding that the contents of SEL are narrower and focus on students' emotional and social aspects, they are unable to provide appropriate educational measures. Thus, to successfully apply the SEL framework in Vietnam, it is not possible to innovate simultaneously, but must change by each stage, each academic year so that teachers have time to train and research on different ways to integrate SEL into subject areas and educational activities. Also, it has time for students to develop SEC step by step through the academic year, meeting the restructured requirements of the 2018-general educational curriculum. With this orientation, it could be proposed the continuous SEL application from primary to secondary education.

This study's limitation was the self-reported data from students and core teachers. Therefore, it was difficult to avoid the impact of subjective factors from students, teachers (the mood of implementation, the level of understanding of the interview questions) as well as the objectivity of the research organization (the conditions for implementing the interview questions, the impact from teachers and researchers, the facilities). However, the findings of the challenges in the integration of SEL in the current educational curriculum, helped the researcher answer the research question posed.

In summary, it could be concluded that the SEL framework could be applied to Vietnamese schools as an educational activity. But before the mass deployment, the training of teachers on how to design SEL-oriented educational activities and SEL-oriented teaching methods is the first thing to do. Besides, the role of other educational forces in schools supporting the implementation of the SEL framework also needs to be addressed. These include the participation of a school psychologist as a professional supporter in student psychology, emotional and social skills for teachers who integrate SEL into their subjects and educational activities, contributing to promoting the school psychology profession has been developing gradually in Vietnam.

\section{Declaration}

This paper represents the work that has been done by Ho Chi Minh City University of Education's Psychology and Education Potential Research Team (Vietnam) and has not been previously submitted in any journal.

The interview data are informed with the consent of the participants for publication and not used for personal interest. 


\section{Disclosure}

The authors report no financial interest or other potential conflicts of interest in this work.

\section{References}

1. Huynh VS. Thuc Hanh Ki Nang Song Danh Cho Hoc Sinh Lop 1 - 9 [Practicing Life-Skill for Students from Grade 1 to 9]. Hanoi: Vietnam Education Publisher; 2017.

2. Kendziora K, Yoder N. When Districts Support and Integrate Social and Emotional Learning (SEL): Findings from an Ongoing Evaluation of Districtwide Implementation of SEL. VA: Education Policy Center at American Institutes for Research; 2016.

3. Greenberg MT, Domitrovich CE, Weissberg RP, et al. Social and emotional learning as a public health approach to education. Future Child. 2017;27(1):13-32. doi:10.1353/foc.2017.0001

4. Collaborative for Academic, Social, and Emotional Learning (CASEL). Key Implementation Insights from the Collaborating District Initiative. Chicago: Author; 2017.

5. Merrell KW, Juskelis MP, Tran OK, et al. Social and emotional learning in the classroom: evaluation of strong kids and strong teens on students' social-emotional knowledge and symptoms. J Appl Sch Psychol. 2008;24 (2):209-224. doi:10.1080/15377900802089981

6. Ministry of Education and Training. Thong Tu 32/2018/TT-BGDDT Ban Hanh Chuong Trinh Giao Duc Pho Thong Moi [Circular No. 32/ 2018/TT-BGDDT Promulgating New General Education Program]. Hanoi: Vietnamese Government Publishing Service; 2018.

7. Beamish W, Bryer F. Teaching for social and emotional learning. In: Garvis S, Pendergast D, editors. Health and Wellbeing in Childhood. The UK: Cambridge University Press; 2017:197-209.

8. Antognazza D, Kapler D. Tai Lieu Tap Huan Giao Duc Tri Tue Cam Xuc - Kinh Nghiem the Gioi Va Ung Dung Vao Viet Nam [Training Material for Emotional Intelligence Education - World Experience and Application to Vietnam]. Ho Chi Minh City: Ho Chi Minh City University of Education Publisher; 2017.

9. Van Huynh S, Giang VT, Nguyen TT, et al. Correlations between Components of Social Emotional Learning of Secondary School Students in Ho Chi Minh City, Vietnam. Euro J Cont Edu. 2019;8 (4):790-800.

10. Van Huynh S, Tran-Chi VL, Nguyen TT. Vietnamese Teachers' Perceptions of Social-Emotional Learning Education in Primary Schools. Euro J Cont Edu. 2018;7(4):874-881.

11. Son HV. Social Awareness andResponsible Decision Making of Students in Grade 4 and 5 in Viet Nam. J Edu Hu Dev. 2018;7(4):7-15.

12. Huynh VS, Tran L. Giao Duc Nang Luc Cam Xuc Xa Hoi Tiep Can Theo Mo Hinh SEL Trong Dao Tao Boi Duong Giao Vien Hien Dai [Educating the Social Emotional Competence to Follow the SEL Model in Modern Teacher Training and Retraining]. Proceedings of the International Conference Training and Retraining of General Teachers, Managers of General Education Institutions and Pedagogical Teachers. Vietnam: Ho Chi Minh City University of Education;2017. 2017 Sep 18.

13. Dang TCH, Nguyen TXP, Giang TV. Ung Dung Mo Hinh Giao Duc Nang Luc Cam Xuc - Xa Hoi Vao Giao Duc Ky Nang Song Cho Hoc Sinh Tieu Hoc Tu Goc Nhin Thuc Tien [Application of SEL Education Model to Life Skills Education for Primary School Students from a Practical Perspective]. Proceeding of the Conference on Experimental Application of SEL Model in Life Skills Education Activities in Primary Schools; Vietnam: Ho Chi Minh City University of Education;2018. 2018 Oct 25.
14. Nguyen TT. Ung Dung Mo Hinh Giao Duc Nang Luc Cam Xuc - Xa Hoi Vao Hoat Dong Giao Duc Cap Trung Hoc Co so [Applying an Emotional-Social Competence Education Model to Secondary Education Activities]. Hanoi: Vietnamese Government Publishing Service; 2019.

15. Ho Chi Minh City Department of Education and Training. Cong Van Ngay 12/4/2018 Cua so GD\&DT Ve Viec Bao Cao Tinh Hinh Trien Khai Cong Tac Giao Duc Ky Nang Song Trong Nha Truong Pho Thong [Official Letter Dated 12/4/2018 of Department of Education and Training About the Report on Implementation of Life Skills Education in High Schools]. Ho Chi Minh City: Vietnamese Government Publishing Service; 2018.

16. Creswell JW, Poth CN. Qualitative Inquiry and Research Design: Choosing Among Five Approaches. CA: Sage publications; 2016.

17. Ministry of Education and Training. Thong Tu 20/2018/TT-BGDDT Quy Dinh Ve Chuan Nghe Nghiep Giao Vien Co so Giao Duc Pho Thong Duoc Bao Ban Hanh 22/8/2018 [Circular No. 20/2018/TTBGDDT Providing Professional Standards for Teachers of General Education Institutions, Issued on August 22, 2018]. Hanoi: Vietnamese Government Publishing Service; 2018.

18. Guest G, MacQueen KM, Namey EE. Applied Thematic Analysis. CA: Sage publications; 2011.

19. World Health Organization. Skills for Health: Skills-Based Health Education Including Life Skills: An Important Component of a ChildFriendly/Health-Promoting School. The World Health Organization; 2013.

20. Golinkoff DGSRM, Hirsh-Pasek K. Play= Learning: How Play Motivates and Enhances Children's Cognitive and Social-Emotional Growth. The UK: Oxford University Press; 2006.

21. Yang C, Bear GG, May H, Curby T. Multilevel Associations Between School-Wide Social-Emotional Learning Approach and Student Engagement Across Elementary, Middle, and High Schools. School Psych Rev. 2018;47(1):45-61. doi:10.17105/SPR2017-0003.V47-1

22. Bullough RV. Hope, happiness, teaching, and learning. In: Bullough RV, editor. New Understandings of Teacher's Work. Holland: Dordrecht; 2011:15-30.

23. De Stercke J, Goyette N, Robertson JE. Happiness in the classroom: strategies for teacher retention and development. Prospects. 2015;45 (4):421-427. doi:10.1007/s11125-015-9372-z

24. Mattison TS. Teacher Mental Health: the Relationships between Teacher Philosophies of Happiness, Emotions and Indicators of Psychological Wellness [dissertation]. The US: University of Texas; 2019.

25. Philippine Ministry of Education and Training. Philippine: deped integrate social-emotional learning public school curriculum; 2009. Available from: http://www.philstar.com/education-and-home/ 495233/deped-integrate-social-emotional-learning-public-school-cur riculum. Accessed August 13, 2009.

26. Humphrey N, Lendrum A, Wigelsworth M. Social and Emotional Aspects of Learning (SEAL) Programme in Secondary Schools: National Evaluation. The UK: Department for Education; 2010.

27. Singapore Ministry of Education and Training. Singapore: Social and Emotional Learning; 2006. Available from: https://www.moe. gov.sg/education/programmes/social-and-emotional-learning. Accessed February 1, 2021. 


\section{Publish your work in this journal}

Psychology Research and Behavior Management is an international, peer-reviewed, open access journal focusing on the science of psychology and its application in behavior management to develop improved outcomes in the clinical, educational, sports and business arenas. Specific topics covered in the journal include: Neuroscience, memory and decision making; Behavior modification and management; Clinical

applications; Business and sports performance management; Social and developmental studies; Animal studies. The manuscript management system is completely online and includes a very quick and fair peer-review system, which is all easy to use. Visit http://www. dovepress.com/testimonials.php to read real quotes from published authors.

Submit your manuscript here: https://www.dovepress.com/psychology-research-and-behavior-management-journal 